Article

\title{
From Coopetition to Hyper-Coopetition: Focusing on a New Paradigm of Heterogeneous Organizational Relationship in the High-Tech Industry
}

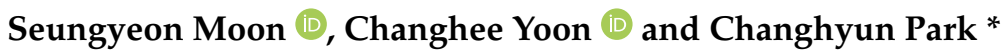 \\ Graduate School of Management of Technology, Sungkyunkwan University, Suwon 16419, Korea; \\ symoon@skku.edu (S.M.); ch100.yoon@skku.edu (C.Y.) \\ * Correspondence: pchrgc@skku.edu
}

check for updates

Citation: Moon, S.; Yoon, C.; Park, C. From Coopetition to HyperCoopetition: Focusing on a New Paradigm of Heterogeneous Organizational Relationship in the High-Tech Industry. Sustainability 2022, 14, 440. https://doi.org/ $10.3390 /$ su14010440

Academic Editor: Fernando Almeida

Received: 2 December 2021 Accepted: 29 December 2021 Published: 31 December 2021

Publisher's Note: MDPI stays neutral with regard to jurisdictional claims in published maps and institutional affiliations.

Copyright: (c) 2021 by the authors. Licensee MDPI, Basel, Switzerland. This article is an open access article distributed under the terms and conditions of the Creative Commons Attribution (CC BY) license (https:/ / creativecommons.org/licenses/by/ $4.0 /)$.

\begin{abstract}
In this study, we proposed the concept of hyper-coopetition based on an investigation of the inter-organizational relationships of chipmakers. Hyper-coopetition is distinguished from traditional coopetition by having companies in heterogeneous industries as participants, whereas traditional coopetition is a relationship between competitors in the same industry. To investigate antecedents and processes of hyper-coopetition, we established the conceptual framework of hyper-coopetition through a literature review. We conducted a case study on leading chipmakers, including Intel, Samsung, and Nvidia, to investigate antecedents and processes of the chipmakers' hyper-coopetition. By examining hyper-coopetition, we contributed to the relevant academic field by introducing hypercoopetition, its typology, and a new research agenda. The analysis result also brought managerial implications for companies in a rapidly changing environment.
\end{abstract}

Keywords: hyper-coopetition; inter-industry coopetition; coopetition; inter-organizational relationship; competitive advantage

\section{Introduction}

Due to the intense competition in the market, which has been accelerated by shortened product life cycles and increasingly turbulent technological changes, there is a growing need for inter-organizational relationships for a company to succeed, or, in some cases, even to survive [1,2]. Inter-organizational relationships are necessary for companies because they help to reduce uncertainties and complement their own capabilities [2,3]. Various terms are used to describe inter-organizational relationships, such as multifaceted relationships and inter-organizational collaborations [3-5]; regardless of the particular term used, interorganizational relationships include companies' efforts to cope with the turbulent business environment $[2,4,6]$.

Coopetition - which explains the motives and unique phenomena in the current market environment-is a type of inter-organizational relationship that has recently attracted substantial attention in the management field $[2,4,6]$. Researchers have stated different definitions for coopetition [2,4]. However, the varying definitions share a commonality: coopetition is a relationship between companies in the same industry that simultaneously involves cooperation and competition [2,6-13]. Coopetition is based on the notion that competitors can make for the best partners because they share common interests and the same contexts while having resources useful to other companies in the same market $[1,12,14]$.

Industrial boundaries have recently begun to fade, and companies are increasingly moving beyond their traditional business boundaries to expand their scope by introducing new products and opening new business opportunities [4]. These phenomena of fading industrial boundaries and increasing inter-organizational relationships are common in high-tech industries due to challenges related to constant technology developments and R\&D activities $[13,15]$. These changes can be clearly seen in the semiconductor industry. 
Since 2010, the semiconductor market has grown rapidly with the increasing usage of semiconductors in IT products [15]. Due to the distinct characteristics of the semiconductor industry - such as a short technology life cycle, cumulative innovation, and high R\&D costs-chipmakers are open to cooperating with other companies, including competitors [15-17]. As a result, there has been a significant trend in the semiconductor industry in recent years, wherein chipmakers actively seek new business opportunities and consequently expand their business scope [18-20]. Some companies cooperate with companies in different sectors through partnerships and strategic alliances, whereas others strengthen their capabilities through acquisitions $[3,18,21]$. These efforts have partly been necessitated by the oversaturation of the mobile market and emerging new business opportunities in the automotive market, as chipmakers want to secure value creation potential by expanding their product portfolios and business fields [18,19,22].

However, the term "coopetition" does not fully explain why a company forms interorganizational relationships with companies in heterogeneous industries. Specifically, chipmakers' strategic movements are distinguished from the known term "coopetition" by two points: First, such companies develop cooperative relationships not only with companies in the same industry, but also with companies in different industries to compete against other parties in the market. Second, in some cases, such companies acquire resources and capabilities through acquisitions to seek new opportunities in the market [19]. For example, Intel collaborates with Waymo, a subsidiary of Alphabet Inc., in developing autonomous driving technology using Intel's processing power [23]. In another example, Samsung Electronics acquired Harman International Industries Incorporated-a leader in automotive application components and Audio Video (AV) systems-in 2016 to extend the scope of its business and broaden its business portfolio [18]. Considering the unique characteristics of high-tech companies' inter-organizational relationships with companies in heterogeneous industries, we coined the term "hyper-coopetition" to differentiate this phenomenon from the traditional concept of coopetition. In this study, we investigated the hyper-coopetition of established companies in the semiconductor industry based on the following research questions:

- RQ 1: How does hyper-coopetition differ from traditional coopetition?

- $\quad \mathrm{RQ} 2$ 2: What triggers the formation of hyper-coopetition in the high-tech industry and how it works?

In this study, we investigated hyper-coopetition between companies in the semiconductor industry and the automotive industry to explore this unique phenomenon. Considering the chipmaker's hyper-coopetition is still in progress, we constructed an a priori construct of motives (i.e., antecedents) and the courses of coopetition between participating companies (i.e., processes) based on a literature review. After establishing the a priori construct, we conducted a case study on established semiconductor companies with hyper-coopetitive relationships with other companies working on autonomous driving technologies.

This study contributes to elucidating the antecedents, processes, and typology of hyper-coopetition. In this study, we present a promising topic in strategic management and coopetition research by proposing the concept of hyper-coopetition. In particular, the result of this study is meaningful in that we defined the concept of hyper-coopetition in the high-tech industry based on a literature review and then provided related evidence through a case study.

The rest of this study is structured as follows: Section 2 provides a theoretical background of coopetition and highlights the research gap in extant studies. In Section 3, we introduce the research framework and the details of the content analysis procedure. Section 3 describes the conceptual framework based on a literature review and its propositions, and Section 4 discusses hyper-coopetition among chipmakers. Finally, based on the analysis result, Section 5 presents theoretical implications for academics, as well as managerial implications for companies who want to retain a sustainable competitive edge, before ending with future research directions. 


\section{Theoretical Background}

\subsection{Background of a Company's Pursuit of Coopetition}

A company's outstanding resources and capabilities do not guarantee a competitive edge in the market [24]. To stay competitive in the market, companies form coopetition with rivals $[1,4,7,14,25]$. There are a number of reasons for why a company might engage in a coopetitive relationship with competitors, including environmental uncertainty, limited resources and capabilities, and perceived benefits, such as knowledge sharing and market power $[1,7,14,25]$. These motives are driven mainly by strategic entrepreneurship, which is a company's efforts and activities to attain and retain a competitive edge $[21,26,27]$.

The rapidly changing market environment urges companies not only to adjust their resources and capabilities but also to adapt to changes to survive in the market $[1,28]$. This eventually facilitates companies' participation in inter-organizational or networklevel relationships with other companies $[1,22,29,30]$. Specifically, companies that want to take advantage of business opportunities in an emergent technology market must pursue inter-organizational relationships with companies with complementary resources and capabilities to enter the market by collaboratively developing new technologies $[3,6,18,31]$.

Coopetition, majorly rooted in strategic management, is one of the inter-organizational relationship types [6,28,29]. As illustrated in Figure 1, coopetition refers to a double-sided relationship between competing companies [28]. The origin of the term "coopetition" is unclear; however, it has attracted growing attention from academics since the publication of the book titled "Co-opetition" by Brandenburger and Nalebuff [10,32]. According to Bouncken et al. [2], coopetition can be defined in two ways: A broad definition of coopetition focuses on supply-chain relations, and the actors are implied to include suppliers, consumers, and complementors. Meanwhile, a narrow definition of coopetition focuses on competition in dyadic or network relationships, in which case, actors are implied to include direct competitors in the same market.

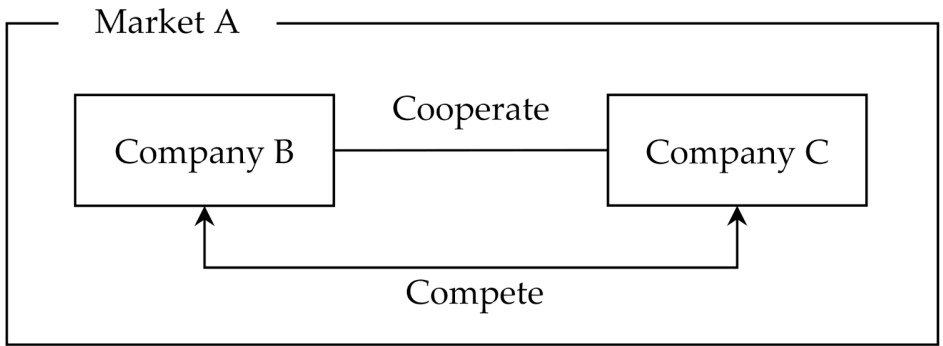

Figure 1. The concept of coopetition.

As shown in Figure 1, competition and cooperation are two core aspects of coopetition; thus, coopetition research emphasizes the importance of the balance between these two aspects for successful coopetition [2,7]. Due to the fact that these two aspects are nondichotomous, some research categorizes coopetition types according to the proportion between cooperation and competition; Crick [7] categorized coopetition into three models (cooperation-dominated, competition-dominated, and balanced relationships), whereas Osarenkhoe [8] suggested four types (monoplayer, contender, partner, and adapter).

Coopetition has been studied from various perspectives, such as the coopetition of established companies, SMEs, and networks [24,33-38]. Studies investigating coopetition in alliances have focused on outcomes of coopetition and influencing factors, such as product market overlap between partners and a scale of the alliance $[35,36]$. For example, Runge et al. [35] examined the influence of an alliance partner with a focus on learning and competitive tension in an R\&D alliance using a dataset of 215 R\&D alliances of US pharmaceutical companies. The analysis result indicated that technological and geographical overlaps increase the company's invention performance, whereas product market overlap hinders the company's invention performance [35]. Coopetition between start-ups and established companies has positive influences on participants by providing access to estab- 
lished companies' resources for start-ups and access to start-ups' innovation capabilities for established companies [33]. Embarking on coopetition with start-ups is hugely affected by a company's prior experience of working with start-ups because companies lacking experience dealing with start-ups tend not to form coopetition with start-ups [34]. For small businesses, coopetition can act as a risk reduction strategy by lessening learning costs and leveraging the experience and resources of a competitor [24]. Besides the above, researchers have also investigated coopetition in networks $[37,39,40]$. These studies discussed various aspects of network coopetition, such as patterns and outcomes. In particular, studies on network coopetition share a common interest in managing relationships with rivals considering the structural properties of networks $[39,40]$.

In summary, extant studies depicted that coopetition can help companies in three ways. First, coopetition allows for companies to access a partner's resources that they need to pursue for the business opportunities that they recognize, and it enhances their performance while helping companies deal with market changes through the strategic management of resources and capabilities (i.e., dynamic capabilities) $[1,4,7,26,29]$. It is nearly impossible for one company to possess all of the resources and capabilities required to create value by developing new technologies, products, or services; therefore, coopetition is inevitable for a firm's survival $[4,14]$. For this reason, coopetition has mainly been discussed in the context of established companies and multi-national enterprises (MNEs) in innovationdriven and high-tech industries (i.e., technologically turbulent fields) [12,22]. Secondly, companies can create value through coopetition, thus increasing the market size and their opportunities [11]. Finally, many studies have verified that coopetition has a positive effect on a firm's innovativeness [3,6,22].

Several factors, including increased access to resources and capabilities, reduced uncertainty, new business opportunities, market expansion, and value creation, were indicated as the antecedents and processes of coopetition. Among the various antecedents of coopetition, the strongest drivers are the need to respond to a dynamic and rapidly changing market environment and the desire to acquire resources and capabilities $[1,2,6,26]$. Despite the usefulness of coopetition from a strategic perspective, coopetition does not fully explain the current increasing demands for cross-industry coopetition (i.e., hypercoopetition) $[18,41]$.

\subsection{The Rise of Hyper-Coopetition in High-Tech Industry}

Traditionally, companies secure resources and capabilities through coopetition with competitors in the same industry as a strategy to stay competitive in the market $[12,25]$. However, today's fast-changing market has pushed companies to extreme competition without industry boundaries, because sticking with one's specialty does not guarantee a company's survival [16,18]. At present, due to oversaturation of the market, traditional coopetition is somewhat insufficient for companies that want to achieve a competitive edge; therefore, it is necessary for companies to explore new opportunities and broaden their business portfolios outside of their current business scope [19].

Fading industrial boundaries and fundamental changes in traditional technology sectors triggered by technology convergence have led to hyper-coopetition between companies in heterogeneous industries $[4,18,42]$. Through hyper-coopetition, companies seek external help from other companies with common interests in the market $[8,13,15,43]$. In hyper-coopetition, companies either make partnerships with companies in different industries, acquire companies in different industries, or acquire companies that have capabilities to extend their value creation potential, as well as the range of prospective target markets $[3,18,19,21,22]$.

Like coopetition, the concept of hyper-coopetition is not entirely new. There are several existing concepts that are partially related to hyper-coopetition, such as cross-industry mergers and acquisitions (M\&As), as well as strategic alliances and partnerships between companies in heterogeneous industries $[3,18,21]$. There are two significant differences between coopetition and hyper-coopetition: (1) whether it happens between companies in 
the same industry or in different industries, and (2) whether it involves a broad definition of cooperation, such as acquisition, while forming a relationship.

The concept of hyper-coopetition comprises two basic principles: cross-industry cooperation and competition between groups of partners from heterogeneous industries (See Figure 2). In Figure 2, there are four companies colored in either yellow or blue. Companies in the same industry (i.e., companies B and C, companies D and E) share the same color. Companies are linked with a solid line to indicate their cooperative relationship, which can appear in various forms, such as partnerships, acquisitions, and alliances. As shown with arrows, companies participating in hyper-coopetition compete as a group with competing companies by leveraging hyper-coopetitive relationships in the market.

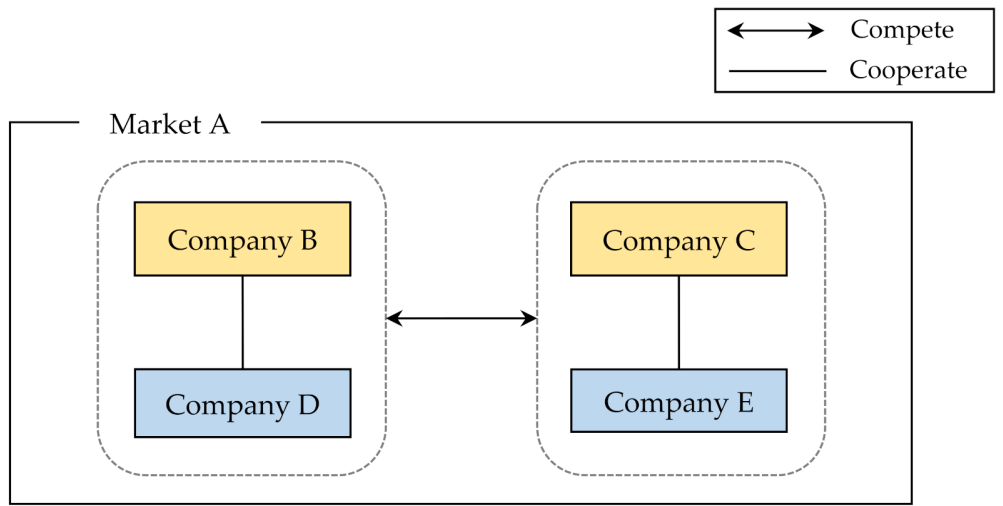

Figure 2. The concept of hyper-coopetition.

\subsection{A Priori Construct of Hyper-Coopetition in the High-Tech Industry}

Based on the literature review, we constructed an a priori construct consisting of two parts: companies' motives (i.e., antecedents) to form hyper coopetitive relationships with companies from different industries and how companies utilize hyper-coopetition (i.e., process) to achieve strategic goals.

\subsubsection{Antecedents}

Antecedents of hyper-coopetition consist of two parts: behavioral traits, as well as resources and capabilities. Behavioral traits describe a company's motives of hypercoopetition according to each company's behavioral properties, such as its entrepreneurial mindset, innovative mindset, proactivity, and prior experience $[7,26]$. These four properties explain why companies initiate hyper-coopetitive relationships from the organizational behavioral aspect. Meanwhile, resources and capabilities explain each company's motives of hyper-coopetition based on each company's limited resources and capabilities.

Behavioral traits and resources and capabilities are the basis of the five major drivers of hyper-coopetition: pressures for innovation (i.e., innovative mindset), sensing new opportunities (i.e., entrepreneurial mindset and proactivity), pursuit of competitive advantage (i.e., entrepreneurial mindset), the pursuit of leveraging external resources (i.e., resources and capabilities), and a positive experience of partnering with other companies (i.e., prior experience) $[1,17,26,28,30]$. Since major drivers of hyper-coopetition are mostly linked to and can be explained by dynamic capabilities (i.e., sensing, seizing, and reconfiguring), we describe each driver based on the dynamic capabilities view.

Let us first consider the case of the first driver, pressures for innovation. Companies in high-tech industries frequently face pressures for continuous innovation due to the relatively short technology and product life cycle compared to those in other industries $[1,28,30]$. Companies attempt to overcome difficulties that they face in the market by reconfiguring their resources and capabilities through forming and participating in hyper-coopetition with the goal of developing new products (services) or technologies $[1,15,44]$. 
The second and third drivers are closely related to the sensing capability. Companies that are exploring new business opportunities to expand their scope of business may enter a new market $[7,9,18,26,27]$. A company's craving for business opportunities is closely related to its pursuit of a competitive edge, which, in turn, directly influences its performance $[1,21,26]$.

The fourth driver-the pursuit of leveraging external resources-is related to the reconfiguring capability. Due to heterogeneous resources and capabilities, companies pursue hyper-coopetition to increase their performance by utilizing their partners' resources and capabilities that they themselves are lacking $[2,7,15,18,22,29]$. A company's reputation in the market is also an important factor in choosing a potential partner and making a decision to participate in hyper-coopetition, because companies can benefit from the partner's influence over the industry [14].

Lastly, a positive partnering experience with other companies influences a company's decision to form and participate in hyper-coopetition $[5,14,30]$. Prior experience comprises a company's past experiences with various types of business cooperation, including partnerships, alliances, coopetition, and joint ventures. For example, the past relationship between companies positively influences the transformation of that former relationship into hyper-coopetition [5]. Further, past experience helps companies to develop future hyper-coopetitive relationships and better manage such relationships [5,14].

\subsubsection{Process}

Once hyper-coopetition has formed, companies exploit hyper-coopetitive relationships with partners in three ways: co-developing new technologies and advanced technologies, utilizing/acquiring the partner's resources and capabilities, and leveraging the partner's market power [30]. In high-tech industries, due to the fast-changing environment and technological resources required, developing new technologies and advancing one's current technological level requires collaborative efforts among stakeholders [5]. Since each company has limited resources and capabilities, companies try to form hyper-coopetitive relationships with partner companies that have resources and capabilities that they themselves are lacking [21]. Through hyper-coopetition, companies co-develop technologies and conduct $R \& D$ while reducing the costs, uncertainties, and risks associated with conducting R\&D alone $[3,13,15,30]$.

Participating in hyper-coopetition gives companies a chance to utilize the resources and capabilities of partnering companies $[1,4,13,14]$. Due to the fact that knowledge is a major source of competitive edge and innovations, hyper-coopetition is particularly important for companies who want to complement and extend their knowledge base $[1,3,7,14,31]$. Through acquisitions, companies can extend their capabilities by gaining the target company's resources and capabilities $[18,21,41]$. Therefore, if companies have nearly identical resources and capabilities, hyper-coopetition is unlikely to happen [29]. By combining and using their partners' resources and capabilities, companies can create new opportunities and improve their performances $[1,14,44]$.

In considering a potential partner company, not only do resources and capabilities matter, but so does the potential partner's position in the market $[2,18,26,30]$. By forming and participating in hyper-coopetition, companies can benefit from a partner's market position. Small- and medium-sized enterprises (SMEs) participate in hyper-coopetition to overcome their low market presence by leveraging a partner's market power [2]. Companies want to expand their business by entering a new market form and participating in hyper-coopetition with leading companies in the target field of interest $[18,26,30]$. Hypercoopetition with a leading company enables companies to gain access to the new market easily, as well as to have a direct link to companies in the field of interest [18]. 


\section{Research Method}

This study aims to derive a definition of hyper-coopetition and to develop a conceptual framework regarding antecedents, processes, and typology of hyper-coopetition in the hightech industry. Since the notion of hyper-coopetition has emerged recently, the qualitative approach is more appropriate to define the new concepts. Besides, our study is constructed using an inductive approach, as presented in Figure 3, "building theory from cases," which was described by Eisenhardt $[45,46]$. This research strategy uses rich, real-world, and empirical evidence as sources of propositions, theoretical constructs, and/or a new theory [46]. Due to the fact that the process of building theory from cases is to construct theoretical construct (i.e., conceptual framework) by inducing from case data, it has been described as an inductive approach $[45,46]$.

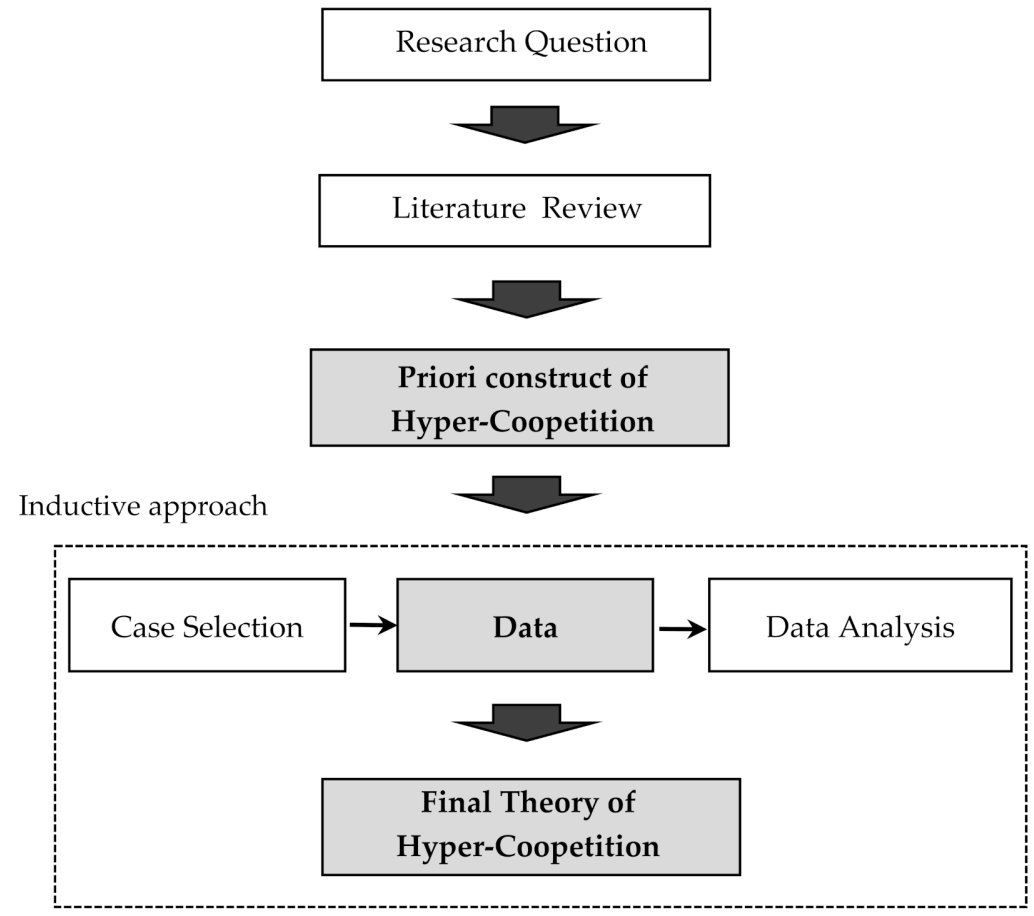

Figure 3. Research framework based on inductive approach.

We defined the research questions first listed in Section 1 based on a solid foundation (i.e., the conceptual framework) rooted in the existing literature. Then, a priori construct of hyper-coopetition was established after reviewing the extant studies to elucidate the typology, antecedents, and processes characteristics of hyper-coopetition in the high-tech industry $[45,46]$. After establishing a priori construct, case study was conducted using cases of established semiconductor companies with hyper-coopetitive relationships with other companies working on autonomous driving technologies. The core of this approach is an inductive process of building a conceptual framework from the case study. In social sciences, there is a long history of building conceptual frameworks and theories using case studies; academics have emphasized the value and strengths of this approach [45-47]. A case study typically involves observing a specific phenomenon to deeply understand it, which may lead researchers to form a theory based on their observations [31,46]. However, existing studies have also shown that there is no widely accepted process for building a theory from case studies [47]. Considering the theory-building processes that have been described in existing studies, we conducted a case study based on four phases: case selection, data collection, data analysis, and constructing the final theory of hyper-coopetition.

In the case selection phase of the inductive approach, we used a theoretical sampling approach to select appropriate cases that best suit the research questions in Section 1. According to Eisenhardt [45], theoretical sampling - an opposite method to random and 
statistical sampling - can help a researcher to select appropriate cases. In addition, researchers can use theoretical sampling to choose cases that can extend current theoretical understandings and emergent theories [45].

We selected the target companies for the case study based on two points: an initial search of Factiva, a global news database operated by Dow Jones \& Company (New York, NY, USA), and business model types in the semiconductor industry. The initial search has provided a glance of the current status of hyper-coopetitive relationships in the semiconductor industry. Through this initial search, we identified several companies that have actively formed and maintained collaborative relationships with automotive makers and automotive components suppliers: Intel (Santa Clara, CA, USA), ARM (Cambridge, UK), Infineon (Neubiberg, Germany), NXP (Eindhoven, The Netherlands), Samsung (Suwon, Korea), and TSMC (Hsinchu, Taiwan).

After the initial search, we selected target companies for the case study in consideration of business model types in the semiconductor industry. In general, companies in the semiconductor industry can be classified into three types based on whether they have design and production capabilities. Companies such as Intel and Samsung Electronics, which are capable of both designing and producing chips, are classified as integrated device manufacturers (IDM). Meanwhile, a fabless company only designs chips but cannot produce them, whereas a foundry company does not design chips and only has a production facility, wherein it produces devices on a consignment basis for IDMs and fabless companies. We selected three companies in consideration of different business typesamong IDMs, foundries, and fabless companies-and the degree of activity in terms of hyper-coopetitive relationships with companies in heterogeneous industries: Intel (IDM), Samsung Electronics (IDM \& Foundry), and Nvidia (Fabless). Since all of the business models in semiconductor industry are considered with hyper-coopetitive relationships with companies in heterogeneous industries, selected cases are well-fitted with the purpose of our research questions.

In the data collection phase of inductive approach, we retrieved data from multiple sources, such as corporate websites, Factiva, CNET, and EE Times. According to Yin [48], using multiple data sources allows for the resultant findings to be more convincing by providing various perspectives on a specific issue. In this study, we used secondary data as a major source of case study. The secondary data are pre-existing data collected by someone other than researcher, which have been used in qualitative and quantitative research [48,49]. Media outlets, such as news websites and corporate newsrooms, provide the latest events in the market and strategic activities of companies [50]. In order to investigate a company's strategic efforts (i.e., hyper-coopetition), we used secondary data over several years [50,51].

Other qualitative data, such as interviews with executives, were not considered in this study, since the typology, antecedents, and processes characteristics of hyper-coopetition cannot be extracted precisely without background knowledge. Table 1 briefly summarizes each data source along with measured data and how to measure data. We used keywords such as 'semiconductors', 'autonomous driving', 'partnership', and 'collaboration' to extract data from the sources. To comprehensively analyze each company's hyper-coopetitive activities, we did not limit the search period so that we could extract as many relevant articles as possible. We collectively retrieved 270 articles from four sources and then conducted qualitative coding using ATLAS.ti 9 software to analyze retrieved articles. 
Table 1. Data sources and measured data for case study.

\begin{tabular}{|c|c|c|c|c|}
\hline Sources & Description & $\begin{array}{l}\text { Number of } \\
\text { Articles }\end{array}$ & $\begin{array}{l}\text { Measured } \\
\text { Data }\end{array}$ & How to Measure Data \\
\hline $\begin{array}{l}\text { Corporate } \\
\text { websites }\end{array}$ & $\begin{array}{l}\text { Companies' official websites that provide articles } \\
\text { on corporate policies and major achievements } \\
\text { through a so-called newsroom menu. }\end{array}$ & 61 & & \\
\hline Factiva & $\begin{array}{l}\text { A global news database operated by Dow Jones \& } \\
\text { Company. Factiva's strength lies in the vast } \\
\text { amount of data because it provides data from } \\
\text { more than } 32,000 \text { sources, such as newspapers } \\
\text { and magazines. }\end{array}$ & 133 & $\begin{array}{l}\text { Antecedents, } \\
\text { processes, and }\end{array}$ & $\begin{array}{l}\text { - Antecedents and } \\
\text { processes are coded } \\
\text { using Atlas.ti } \\
\text { Each case's }\end{array}$ \\
\hline CNET & $\begin{array}{l}\text { A renowned American website that offers } \\
\text { industry news, technology articles, and product } \\
\text { reviews with a focus on the electronics market. }\end{array}$ & 53 & & $\begin{array}{l}\text { hyper-coopetition type } \\
\text { is selected out of four } \\
\text { types }\end{array}$ \\
\hline EE Times & $\begin{array}{l}\text { An industry-specific news media outlet owned by } \\
\text { AspenCore Media. EE Times provides news and } \\
\text { analysis of the latest technology in the electronics } \\
\text { industry. }\end{array}$ & 23 & & \\
\hline
\end{tabular}

Qualitative coding is one of the qualitative data analysis methods, and it is frequently used in studies employing case studies, content analyses, and systematic reviews [52]. Qualitative coding involves assigning "codes" that best describe meanings in sentences, phrases, and paragraphs [53]. It allows for a researcher to extract meanings from qualitative data and synthesize initial findings into advanced outcomes, such as business implications and theories [52,53].

In the data analysis phase of inductive approach, this study conducts qualitative coding with three steps: open coding, axial coding, and selective coding. In the first step, we use open coding to break down qualitative data into small segments (i.e., codes) to examine the concepts and ideas in the data $[49,53]$. Open coding is also called initial coding because it initiates the first cycle of the coding procedure [53]. Various codes are created during open coding, which serves as a foundation for the case analysis. The codes describe each company's motives, goals, and actions related to hyper-coopetition. After the open coding, we use axial coding to classify and reorganize codes into categories $[49,53]$. Through axial coding - which embraces semantically related codes-we derive elements constituting the conceptual framework of hyper-coopetition, such as antecedents and processes. Lastly, we use selective coding to derive a core concept that explains and represents the concerned phenomenon [49]. The core concept links other categories and makes a logical flow that explains the relevant phenomenon through the results of empirical findings [49,52].

Based on the selective coding, we constructed a conceptual framework using the elements derived from axial coding and suggested hyper-types to explain each company's unique properties of hyper-coopetition. Based on qualitative coding, we examined each company's hyper-coopetition in terms of the types, their motives (i.e., antecedents), and how hyper-coopetition progresses (i.e., process) as the last phase of inductive approach. Section 4 describes the analysis results of the typology, antecedents, and processes in hyper-coopetition of three chipmakers.

\section{Hyper-Coopetition of Chipmakers}

In this work, we conducted a case study to examine the hyper-coopetition of chipmakers while focusing on autonomous driving technologies. In this section, we first discuss the typology of hyper-coopetition, and then discuss the antecedents and processes of hypercoopetition in the semiconductor industry. We present the detailed analysis results in connection with the research questions: RQ 1 (How does hyper-coopetition differ from the traditional coopetition?) and RQ 2 (What triggers the formation of hyper-coopetition in the high-tech industry and how it works?). In order to provide a comprehensive and consistent picture of cases, we described case analysis results based on thick description [49,54]. Thick 
description, which was introduced by Geertz, focuses on thickly describing actions in consideration with its contexts; in other words, researchers provide a detailed description of the case itself $[49,55]$. We also provided related evidences from cases in the form of a case ID at the end of each sentence (for details, see Appendix A).

\subsection{Hyper-Coopetition Typology of Intel, Nvidia, and Samsung}

In this study, we defined hyper-coopetition as a relationship that consists of companies from heterogeneous industries cooperating with each other in order to achieve strategic goals, such as attaining a competitive edge, securing resources and capabilities, and broadening business areas. While competing in the market, participants in hyper-coopetition compete as a group with competitors. Hyper-coopetition has two unique properties: a broad definition of cooperation and a cross-industry interorganizational relationship. Hypercoopetition encompasses various types of interorganizational relationships-including acquisitions, partnerships, alliances, and consortia-whereas coopetition only accepts relationships that guarantee organizational separation as cooperative relationships; therefore, M\&As mark the end of coopetition [56]. Hyper-coopetition can also be formed between companies in vertical or horizontal relationships $[29,56]$. Based on these findings, we derive the hyper-coopetition typology shown below in Figure 4.

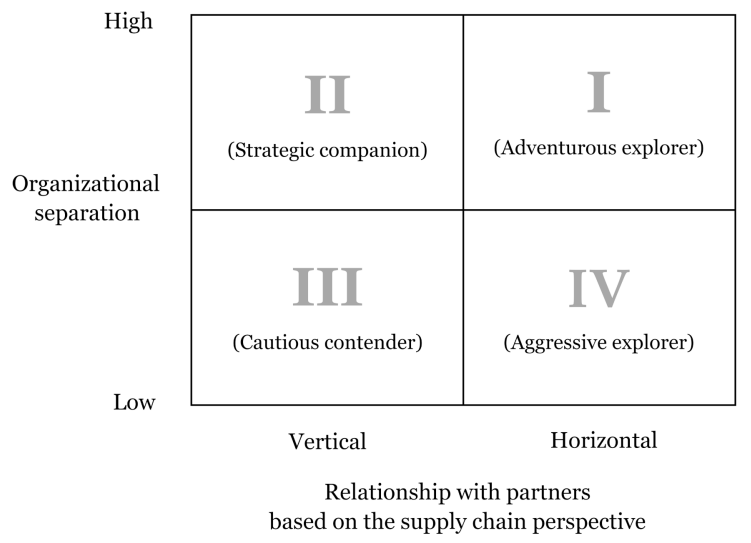

Figure 4. Hyper-coopetition types.

Traditional coopetition has focused on relationships between competitors, such as that between Samsung and Sony [4]. Due to the fact that the concept of coopetition typically focuses on direct competitors in the same market, it is categorized into three types (cooperation-dominated, competition-dominated, and balanced relationships) depending on the relative degree of cooperation and competition between companies [2,7]. In contrast to coopetition, hyper-coopetition is a relationship between companies from heterogeneous industries that encompasses both cooperative relationships and acquisitions; therefore, it is natural to categorize hyper-coopetition from two standpoints: a partner's position in the supply chain (vertical/horizontal) and the foundation of hyper-coopetition in terms of organizational separation (hyper-coopetition based on collaboration/hyper-coopetition based on acquisition). A two-by-two matrix, which divides the concept into four equal quadrants, is useful to decide, along with criteria, and is composed in order to identify different typologies of hyper-coopetition in Figure 4, along with the criteria of the relationship with partners and organizational separation according to the literature review.

In Figure 4, the x-axis indicates whether the relationship between partners is horizontal or vertical from the supply chain perspective, whereas the $y$-axis shows whether interorganizational separateness is secured between the participants. Considering the unique features of each type, we named the four different types as 'adventurous explorer', 'strategic companion', 'cautious contender', and 'aggressive explorer'. All four types describe companies' efforts to secure competitiveness in the market through hyper-coopetition. However, the major difference between the top side and the bottom side is the manner in 
which the hyper-coopetition has been formed; specifically, whether it was formed through a moderate approach that maintains each partner's organizational separateness or an aggressive approach that lacks organizational separateness. In the adventurous explorer (type I) and strategic companion (type II) types, companies cope with the changing market environment by forming and participating in hyper-coopetition with heterogeneous companies based on the moderate approach, such as through collaborations, partnerships, and consortia. By contrast, in the cautious contender (type III) and aggressive explorer (type IV) types, companies take aggressive approaches to gain a competitive edge by expanding the scope of their business in both the vertical and horizontal directions. For example, companies showing type III and IV hyper-coopetition actively pursue acquisitions to ensure the resources and capabilities that they require for success.

Since the 2010s, chipmakers have become eager to diversify their business channels through various methods-such as acquisitions and partnerships with companies having relevant resources and capabilities - to develop new sources of profit $[18,19]$. This phenomenon is not confined to a few chipmakers in the market, as it has been caused by technological shifts in the market, as well as a slower pace of Moore's Law [15,19]. The transformation to a data-centric market and gradual changes in the automotive industry through the application of various technologies, including AI and 5G, seem to have affected the choices made by chipmakers [19]. Each case shows a different approach taken by chipmakers dealing with technological challenges in terms of their choices of partner selection, the target fields, and the types of hyper-coopetition.

In general, Intel devotes itself to catching up with competing companies and securing its position in the rush for autonomous driving technologies by considering all of the options and pulling in every resource they have. Considering its past experience with the transition from PCs to smart phones, which opened up substantial opportunities, Intel actively engages in hyper-coopetitive relationships with various companies relevant to autonomous driving technologies (Case ID: Intel-4,7,11,12,18,20). Intel's partners range from car makers (i.e., original equipment manufacturers; OEMs) to mapping companies. Intel has aggressively expanded its position in the autonomous driving field by pursuing both horizontal and vertical hyper-coopetitive relationships. The analysis result indicates that Intel focuses on four major target fields of hyper-coopetition: driverless mobility-asa-service (MaaS) (i.e., mobility), maps for autonomous driving vehicles (i.e., navigating tech), autonomous driving platform (i.e., platform), and in-vehicle infotainment (i.e., connectivity). Using its sensor, navigating tech, and autonomous driving platform, Intel collaboratively develops driverless MaaS with partnering companies, such as Volkswagen, Willer, and Habtoor (Case ID: Intel-2,8-10,15,16,19). Intel also concentrates on developing and advancing technologies for autonomous driving, including the real-time updating of HD maps and open autonomous driving platforms that can be customized for a customer's particular needs (Case ID: Intel-1,3,5,6,9,10). Due to the fact that cars have become capable of various functions, just like smart phones, Toyota and Warner Bros are collaborating with Intel to develop in-vehicle infotainment systems, leveraging Intel's computing power (Case ID: Intel-14,17).

On the other hand, Nvidia, a leader in the field, focuses on increasing its market influence through hyper-coopetition with car makers, tier 1 suppliers, and software companies. Nvidia focuses on two major target fields: its autonomous driving platform (i.e., platform) and mapping for autonomous driving vehicles (i.e., navigating tech). Rather than selling its chips, Nvidia actively pursues hyper-coopetition with companies in heterogeneous industries to promote the usage of its autonomous driving platform (Case ID: Nvidia$2,3,5,7,10,14,19,20,24,26,27)$. As autonomous driving vehicles are currently in a growth stage, promoting companies to use its autonomous driving platform can help Nvidia to secure an early lead in the field through an industry-wide acceptance of its platform. Nvidia is also concentrating on developing navigation tech for autonomous driving vehicles by forming hyper-coopetition with companies, such as Audi, HERE, SK Telecom, and Zenrin (Case ID: Nvidia-1,9,11,16,18,22,25). Similar to Intel, Nvidia's hyper-coopetition also aims 
to facilitate driverless MaaS, but one big difference is that Nvidia targets both driverless MaaS for people and goods; for example, DHL and Paccar develop autonomous driving trucks based on Nvidia's autonomous driving platform (Case ID: Nvidia-6,8,15).

Samsung Electronics' approach to hyper-coopetition in the autonomous driving field shows how Samsung perceives the opportunities opened by autonomous driving technologies. Compared to Intel and Nvidia, the analysis results indicate that Samsung only focuses on business opportunities-such as in-vehicle technology, digital cockpits, and automotive electronics-that can make the most of its strengths and can lead to substantial synergy with its subsidiaries' businesses, rather than focusing on developing autonomous driving platforms. As one of the foremost global electronics manufacturers, Samsung acquired Harman International in 2016 to accelerate its entrance into the in-vehicle technology market [18]. The acquisition of Harman gives Samsung a chance to utilize Harman's expertise in audio electronics, as well as its extensive experience in consumer electronics, to meet the growing demand of OEMs for in-vehicle technology (Case ID: Samsung-1).

As we discussed earlier, the analysis result clearly shows differences in terms of goals in chipmakers' hyper-coopetition. We visualized each company's hyper-coopetition according to hyper-coopetition types in Figure 4. Types of hyper-coopetition are decided depending on the criteria of the relationship with partners and organizational separation for the cases of three chipmakers (See Appendix A). Figure 5 shows the distribution of hyper-coopetition types of each chipmaker according to the analysis results. Intel shows all four types; the most evident hyper-coopetition types were I and II, both of which possessing high levels of organizational separateness. In contrast to Intel, Nvidia's hyper-coopetition is mostly focused on type II. The heterogeneous business approaches of Intel and Nvidia toward the autonomous driving field are reflected in their differing hyper-coopetition types. As we discussed earlier, Intel aggressively promotes hyper-coopetitive relationships with companies in various industries to attain resources and capabilities while staking out its spot in the autonomous driving field. By contrast, Nvidia forms hyper-coopetitive relationships to expand and strengthen its position in the field by attempting to establish its autonomous driving platform as the de facto standard in the market. Finally, Samsung shows type IV hyper-coopetition by pursuing new market opportunities, such as through the acquisition of Harman International, to expand its business scope while pursuing synergy with its resources and capabilities. Due to the fact that an acquisition provides quick access to necessary resources and capabilities, Intel has also shown type IV hypercoopetition by acquiring companies, such as Itseez, Moovit, and Mobileye, to accelerate its penetration into the autonomous driving field.

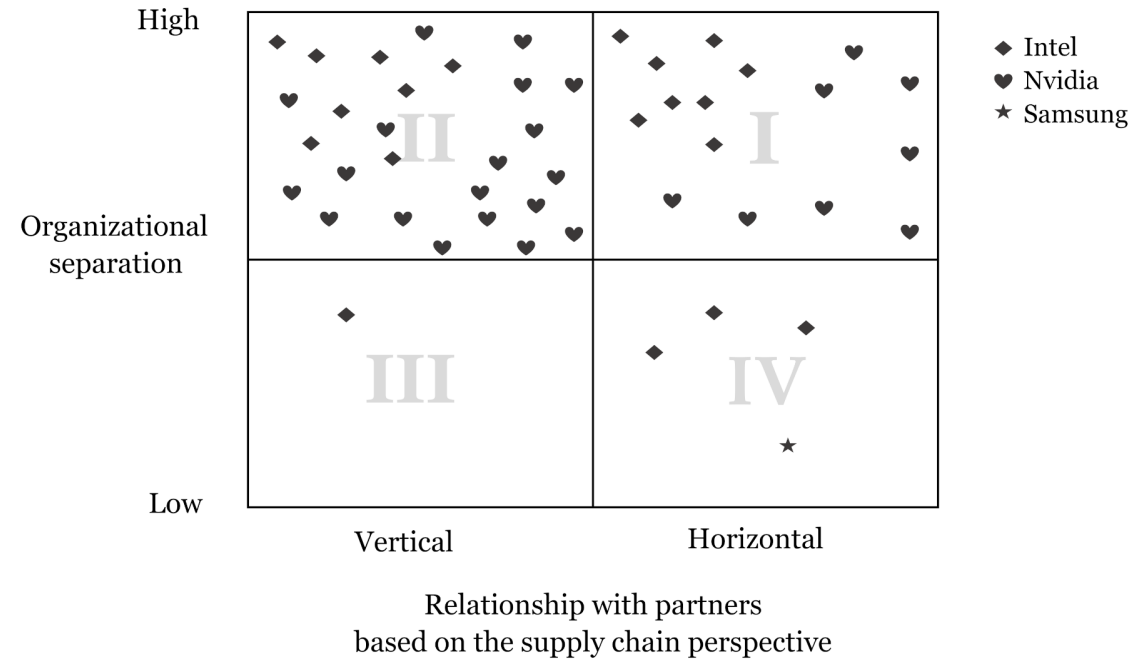

Figure 5. Hyper-coopetition types among chipmakers. 
Proposition 1. A company's unique hyper-coopetition type is shaped according to each company's business approaches and strategies toward the target business field.

\subsection{Antecedents and Processes of Hyper-Coopetition in the Semiconductor Industry}

In this section, we briefly overview the case analysis result, discuss the details of the antecedents and processes of hyper-coopetition that were observed from the case analysis, and then investigate similarities and differences among the three chipmakers. The case analysis result demonstrates the heterogeneous hyper-coopetition motives of major chipmakers and how the hyper-coopetitive relationship operates. Table 2 provides a summary of each chipmaker's antecedents and process of hyper-coopetition. The features of the antecedents and process of chipmakers' hyper-coopetition based on the case analysis result are discussed below.

Table 2. Summary of chipmakers' antecedents and process of hyper-coopetition.

\begin{tabular}{ccccc}
\hline & Antecedents and Processes & Intel & Nvidia & Samsung \\
\hline \multirow{4}{*}{ Antecedents } & Pressures for innovation & Medium & High & High \\
& $\begin{array}{c}\text { Sensing new opportunities } \\
\text { Pursuit of competitive advantage } \\
\text { Pursuit of leveraging external } \\
\text { resources }\end{array}$ & $\begin{array}{c}\text { High } \\
\text { High }\end{array}$ & High & High \\
& $\begin{array}{c}\text { High } \\
\text { Positive partnering experience with } \\
\text { other companies } \\
\text { Co-development }\end{array}$ & Low & Medium & High \\
& $\begin{array}{c}\text { Low } \\
\text { Process }\end{array}$ & High & High & High \\
& $\begin{array}{c}\text { Utilizing/Acquiring a partner's } \\
\text { resources and capabilities } \\
\text { Leveraging a partner's market } \\
\text { power }\end{array}$ & High & Low & High \\
& Medium & High & High \\
\hline
\end{tabular}

The most frequently observed motives for hyper-coopetition were sensing new opportunities and pursuing a competitive advantage. This indicates that chipmakers enthusiastically search for new sources of profit through forming and participating in hypercoopetition with companies from heterogeneous industries. Other antecedents, such as pressures for innovation and the pursuit of leveraging external resources, also facilitate chipmakers' hyper-coopetition. However, among the five major drivers, a positive experience with a partnership has a relatively lower impact on hyper-coopetition.

Intel's hyper-coopetition is mostly triggered by the resources and capabilities of its partnering companies (Case ID: Intel-1,3-7,9,10,17,20). Intel aggressively acquires tech companies to secure resources and capabilities to compete with competitors such as Nvidia, which is the front runner in the autonomous driving technology field (Case ID: Intel$4,7,9,20)$. It seems that Intel views securing resources and capabilities through acquisitions and, in some cases, partnerships, as critical for its success in this competition. This is because Nvidia, which also provides autonomous driving platforms to OEMs, currently has a large market share compared to Intel. In addition, the analysis result indicates that the entrepreneurial mindset also facilitates Intel's hyper-coopetition based on the expectation of new business opportunities with the introduction of autonomous driving vehicles (Case ID: Intel-1,2,5,9,10,15,16,19).

In the case of Nvidia, the behavioral traits-and entrepreneurial mindset and proactivity in particular-are the strongest driver of Nvidia's hyper-coopetition. The computing power demands for autonomous driving vehicles are expected to be 50 to 100 times more than those of advanced vehicles. Considering the potentiality of autonomous driving technologies, its resources and capabilities, and the demands in the market, Nvidia is strategically pushing into the automotive field by developing and providing an autonomous driving platform to its partners (Case ID: Nvidia-2,3,5,7,10,14,9,20,24,26,27). The other motive for hyper-coopetition - proactivity-shows Nvidia's continuous pursuit of innovation and growth. To overcome market saturation in the semiconductor industry and 
the slowed pace of technological advancement, Nvidia seeks new market opportunities through expanding its scope of business by making full use of its resources and capabilities (Case ID: Nvidia-3,6,8,9,11,13-15,18,22,24).

In the case of Samsung, behavioral traits (entrepreneurial mindset and innovative mindset), as well as resources and capabilities (accessing other companies' resources and capabilities and leveraging a partner's reputation), both facilitate its hyper-coopetition. Samsung acquired Harman in 2016 to access Harman's resources and capabilities, and this acquisition was made in consideration of its future strategic value. The acquisition of Harman gave Samsung a chance to utilize Harman's industry-leading expertise in combination with its long experience in consumer electronics and the resources of its subsidiaries (Case ID: Samsung-1). Compared to Intel and Nvidia, Samsung-being a conglomerate-not only considers its own resources and capabilities, but also those of its subsidiaries when selecting potential candidates for hyper-coopetition.

In terms of the process, all three chipmakers devote themselves to co-developing technologies and products related to autonomous driving. However, chipmakers have shown distinctions in terms of how they exploit hyper-coopetition. For example, Intel utilizes a partner's resources and capabilities to co-develop autonomous driving technologies to introduce new products and to enter into the market. By contrast, Nvidia not only co-develops new products and technologies through hyper-coopetition, but also leverages its partner's market power, such as its customer base. In contrast to both Intel and Nvidia, Samsung utilizes all available means, including co-development, utilizing and acquiring a partner's resources and capabilities, and leveraging a partner's market power.

Intel expects new business opportunities in the autonomous industry based on the notion that the introduction of autonomous driving vehicles has opened up chances for chipmakers to create a new source of profit. Considering its strengths, Intel looks for business opportunities in the autonomous driving field, particularly those related to computing power and data center offerings (Case ID: Intel-3,4). To this end, Intel jointly develops autonomous driving vehicles and related technologies with partners. For example, Intel and HERE are collaboratively developing an architecture for the real-time updating of HD maps for autonomous driving vehicles (Case ID: Intel-3). The analysis result also indicates that Intel actively leverages and utilizes its partners' resources and capabilities during the co-development process. In some cases, Intel acquires companies that have the resources and capabilities Intel needs to achieve its hyper-coopetition goals. For example, the acquisition of Mobileye helped Intel to become a one-stop shop offering hardware and software solutions for autonomous driving technologies, thus allowing Intel to quickly achieve its goal (Case ID: Intel-7).

Meanwhile, Nvidia effectively leverages its partners to secure an advantageous position in the market. For example, Nvidia gained the most ground in ride-hailing services by supplying its chips to relevant companies, while Nvidia also dominates the autonomous driving platform with broad partnerships with various OEMs (Case ID: Nvidia-1,4,12,14,15,17,19,21-24). Nvidia quickly responds to transitions in the market by codeveloping autonomous driving technologies through hyper-coopetition, which has helped the company gain the most share in the market. Compared to Intel, Nvidia's proactive approach toward autonomous driving technologies has helped it establish a solid foothold in the autonomous driving technology field.

Similar to Intel and Nvidia, Samsung also uses hyper-coopetition to utilize its partner's resources and capabilities while seeking new sources of profit. The difference between Samsung and other chipmakers is that Samsung actively applies every possible method of hyper-coopetition. By acquiring Harman, Samsung pursued the co-development of in-vehicle infotainment, digital cockpits, and automotive electronics with Harman to meet increasing consumer demands in connection with the development of autonomous driving technologies. Samsung took advantage of its acquisition of Harman as an opportunity to leverage Harman's brands and its position as a market leader in connected car solutions to gain a significant presence in the market. 
Proposition 2. The combination of new business opportunities, a company's desire to secure competitive edge in the market, and pressure for innovation facilitates hyper-coopetition.

Proposition 3. A company's existing resource and capability basis and the decision on how to achieve its goal determine each company's distinctive process of hyper-coopetition.

\section{Conclusions and Future Research}

In this study, we introduced the concept of hyper-coopetition based on extant studies, and we categorized hyper-coopetition into four types. Based on the cases of three chipmakers, we examined the antecedents and processes of hyper-coopetition and derived three research propositions based on a case analysis. The case analysis result showed the different motives of each chipmaker to engage in hyper-coopetition, as well as how each chipmaker's hyper-coopetition progresses. It appears to be the case that a company's strategic objective decides the type of each chipmaker's hyper-coopetition. We derived both theoretical and business implications by investigating hyper-coopetition among chipmakers. We first discuss the theoretical contributions and then discuss business implications for companies facing challenges in the market.

First, we suggested a new concept-hyper-coopetition-to describe the establishment of an interorganizational relationship between companies from heterogeneous industries to achieve strategic goals. Hyper-coopetition is distinguished from the traditional concept of coopetition in two ways: the participants and goals of the interorganizational relationship. Generally, coopetition involves companies in a competitive relationship within the same industry; S-LCD, coopetition between Samsung and Sony, is a classic example of coopetition. By contrast, hyper-coopetition involves companies in heterogeneous industries, such as Nvidia (chipmaker) and Volvo (automaker). The goals of hyper-coopetition are also distinguished from those of coopetition by focusing on expanding the scope of business to uncharted territory along either the vertical or horizontal direction of the supply chain.

Secondly, we suggested the concept of hyper-coopetition and proposed a hypercoopetition typology. We proposed four types (adventurous explorer, strategic companion, cautious contender, and aggressive explorer) of hyper-coopetition in terms of its unique characteristics, such as the relationship between companies (whether one of the companies in the hyper-coopetitive relationship acquires the other company) and the counterpart's position in the supply chain (whether a company is placed in the vertical or horizontal part of the supply chain). By doing so, we were able to classify each chipmaker's hypercoopetition from the case analysis and to discuss company-specific features based on the case analysis result.

Thirdly, investigating empirical evidence regarding hyper-coopetition in the semiconductor industry helped us to extend the current academic field and bring up a new academic agenda. By bringing up a new concept-hyper-coopetition-we extend the research field of coopetition research. In addition, hyper-coopetition research can fill theoretical gaps in the coopetition research field by investigating the interorganizational relationship between companies in heterogeneous industries.

We discovered certain managerial implications for companies under a rapidly changing environment based on the case analysis result. First, companies facing market oversaturation and industry-wide technological changes tend to explore new sources of profit through hyper-coopetition with companies in heterogeneous industries. All three chipmakers actively utilize hyper-coopetition as a means to complement their own resources and capabilities by gaining access to those of their partners.

Secondly, a company that desires a quick entrance into the target market or that desires to catch up with its competitors can leverage hyper-coopetition to acquire the required resources and capabilities from its counterpart. Chipmakers have shown type III and IV hyper-coopetition by acquiring companies that have resources and capabilities that are essential for its success. Intel is a classic example of this; according to the analysis result, Intel has acquired various companies, such as Mobileye (tier 1 supplier), Moovit 
(mapping company), and Itseez (software company), to quickly strengthen its competitiveness by combining its existing resources with the newly acquired resources through hyper-coopetition. This is particularly appropriate for companies aiming to turn the tables before it is too late to challenge the forerunner.

Lastly, hyper-coopetition can help a company to achieve its goal by making full use of each partner company's available resources and capabilities, as well as its relationship with other companies, including its role and market positioning. Each company's hyper-coopetition presents in distinctive ways, and each company's hyper-coopetition type is shaped depending on its particular goal. The case analysis result shows that hypercoopetition's goals (i.e., target fields) vary depending on each company's capabilities and past business experiences. According to the case analysis result, among the three chipmakers, Nvidia seems to employ hyper-coopetition most effectively by considering its market position and relationship with carmakers. For instance, Nvidia has wide connections with OEMs, such as Audi, BMW, and Volvo, to whom it supplies its chips. Based on its past business experience with OEMs and its core capabilities-GPU and AI-Nvidia's target field of hyper-coopetition is the autonomous driving platform, which has helped Nvidia to become the forerunner in autonomous driving technology.

Although we examined the hyper-coopetition of three leading chipmakers, this study has a few limitations: the generalizability of the case analysis result, the criteria for hypercoopetition typology, and the future development of the hyper-coopetition concept. First, it is unknown whether the analysis result applies to other industries because we only examined companies in the semiconductor industry. Therefore, further research is needed to examine whether our findings also apply to other sectors, as well as to expand and deepen the understanding of this unique phenomenon.

Secondly, we suggested two criteria for categorizing hyper-coopetition: organizational separateness and a relationship with partners based on the supply chain perspective. Since hyper-coopetition research remains in an early stage, there are no criteria for hypercoopetition typology due to a lack of consensus in the research field. This necessitates a further discussion on the method used to capture hyper-coopetition typology.

Finally, the concept of hyper-coopetition will be evolved since it is still in the early stage of development. Although research findings regarding the typology, antecedents, and processes of hyper-coopetition give new insights, future research will monitor the future transformation of hyper-coopetition concepts based on new cases in order to deepen theoretical propositions and to provide an avenue for new concepts.

Author Contributions: Conceptualization, S.M.; methodology, S.M.; software, S.M.; validation, C.Y. and C.P.; formal analysis, S.M.; investigation, S.M. and C.Y.; resources, C.Y.; data curation, S.M. and C.Y.; writing-original draft preparation, S.M.; writing-review and editing, S.M. and C.P.; visualization, S.M. and C.Y.; supervision, C.P.; project administration, S.M. All authors have read and agreed to the published version of the manuscript.

Funding: This research received no external funding.

Data Availability Statement: The data presented in this study are available on request from the corresponding author.

Acknowledgments: We would like to express our gratitude to our fellow researcher, Kyounghwan Chin, for giving us valuable insights into the semiconductor industry. We also appreciate Heesang Lee of his comments and suggestions for improving the quality of the manuscript.

Conflicts of Interest: The authors declare no conflict of interest. 


\section{Appendix A}

Table A1. Detailed Analysis Results of Hyper-Coopetition in the Semiconductor Industry.

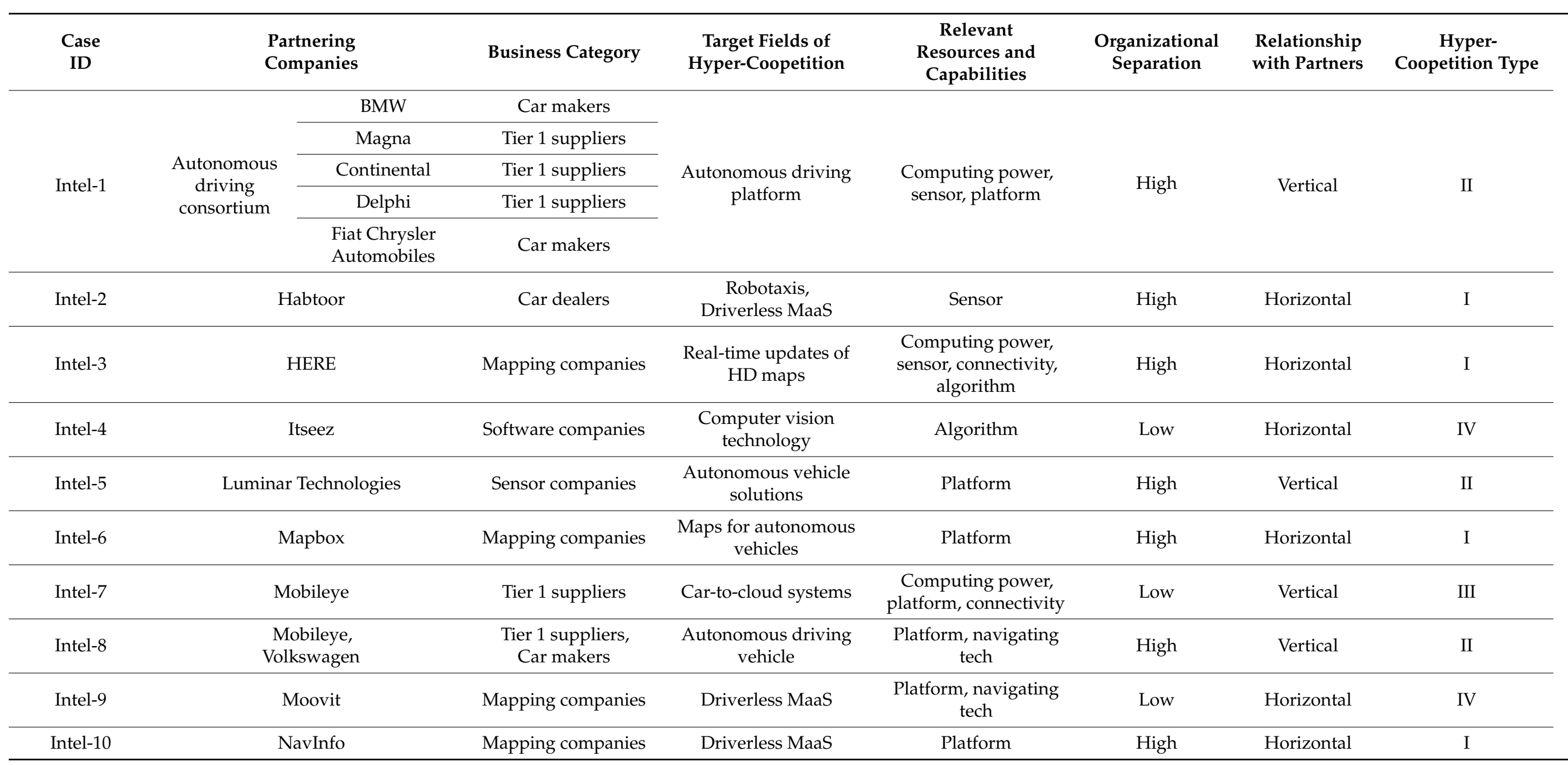


Table A1. Cont.

\begin{tabular}{|c|c|c|c|c|c|c|c|}
\hline $\begin{array}{l}\text { Case } \\
\text { ID }\end{array}$ & $\begin{array}{l}\text { Partnering } \\
\text { Companies }\end{array}$ & Business Category & $\begin{array}{l}\text { Target Fields of } \\
\text { Hyper-Coopetition }\end{array}$ & $\begin{array}{c}\text { Relevant } \\
\text { Resources and } \\
\text { Capabilities }\end{array}$ & $\begin{array}{l}\text { Organizational } \\
\text { Separation }\end{array}$ & $\begin{array}{l}\text { Relationship } \\
\text { with Partners }\end{array}$ & $\begin{array}{c}\text { Hyper- } \\
\text { Coopetition Type }\end{array}$ \\
\hline Intel-11 & $\mathrm{NIO}$ & Car makers & $\begin{array}{l}\text { Autonomous driving } \\
\text { vehicle }\end{array}$ & $\begin{array}{l}\text { Computing power, } \\
\text { sensor, platform, } \\
\text { navigating tech }\end{array}$ & High & Vertical & II \\
\hline Intel-12 & SAIC Motor & Car makers & $\begin{array}{l}\text { Autonomous driving } \\
\text { vehicle }\end{array}$ & $\begin{array}{l}\text { Computing power, } \\
\text { sensor, platform }\end{array}$ & High & Vertical & II \\
\hline Intel-13 & SK Telecom & $\begin{array}{l}\text { Communication } \\
\text { services }\end{array}$ & $\begin{array}{l}\text { Vehicle-to-everything } \\
\text { (V2X) }\end{array}$ & Algorithm & High & Horizontal & I \\
\hline Intel-14 & Toyota & Car makers & In-vehicle infotainment & Computing power & High & Vertical & II \\
\hline Intel-15 & $\begin{array}{c}\text { Transdev Autonomous Transport } \\
\text { System, Lohr Group }\end{array}$ & Mobility services & $\begin{array}{c}\text { Autonomous driving } \\
\text { shuttle }\end{array}$ & Platform & High & Horizontal & I \\
\hline Intel-16 & $\begin{array}{c}\text { Volkswagen, } \\
\text { Champion Motors }\end{array}$ & $\begin{array}{l}\text { Car makers, } \\
\text { Car dealers }\end{array}$ & Driverless MaaS & Platform & High & Vertical & II \\
\hline Intel-17 & Warner Bros & $\begin{array}{l}\text { Entertainment } \\
\text { companies }\end{array}$ & $\begin{array}{c}\text { In-vehicle } \\
\text { Entertainment }\end{array}$ & Computing power & High & Horizontal & I \\
\hline Intel-18 & Waymo & Car makers & $\begin{array}{c}\text { Autonomous driving } \\
\text { technology }\end{array}$ & $\begin{array}{l}\text { Computing power, } \\
\text { connectivity }\end{array}$ & High & Vertical & II \\
\hline Intel-19 & Willer & Mobility services & Robotaxis & Platform & High & Horizontal & I \\
\hline Intel-20 & Yogitech & $\begin{array}{l}\text { Semiconductor } \\
\text { design and } \\
\text { verification }\end{array}$ & $\begin{array}{l}\text { Functional security } \\
\text { capability }\end{array}$ & Computing power & Low & Horizontal & IV \\
\hline vidia-1 & Audi & Car makers & $\begin{array}{c}\text { Autonomous driving } \\
\text { technology, 3D } \\
\text { navigation system }\end{array}$ & $\begin{array}{l}\text { Computing power, } \\
\text { platform, algorithm }\end{array}$ & High & Vertical & II \\
\hline Nvidia-2 & Aurora & Software companies & $\begin{array}{l}\text { Autonomous driving } \\
\text { platform }\end{array}$ & Platform & High & Vertical & II \\
\hline Nvidia-3 & Baidu & Internet services & $\begin{array}{l}\text { Autonomous driving } \\
\text { platform, autonomous } \\
\text { driving vehicle software }\end{array}$ & Platform, algorithm & High & Vertical & II \\
\hline
\end{tabular}


Table A1. Cont.

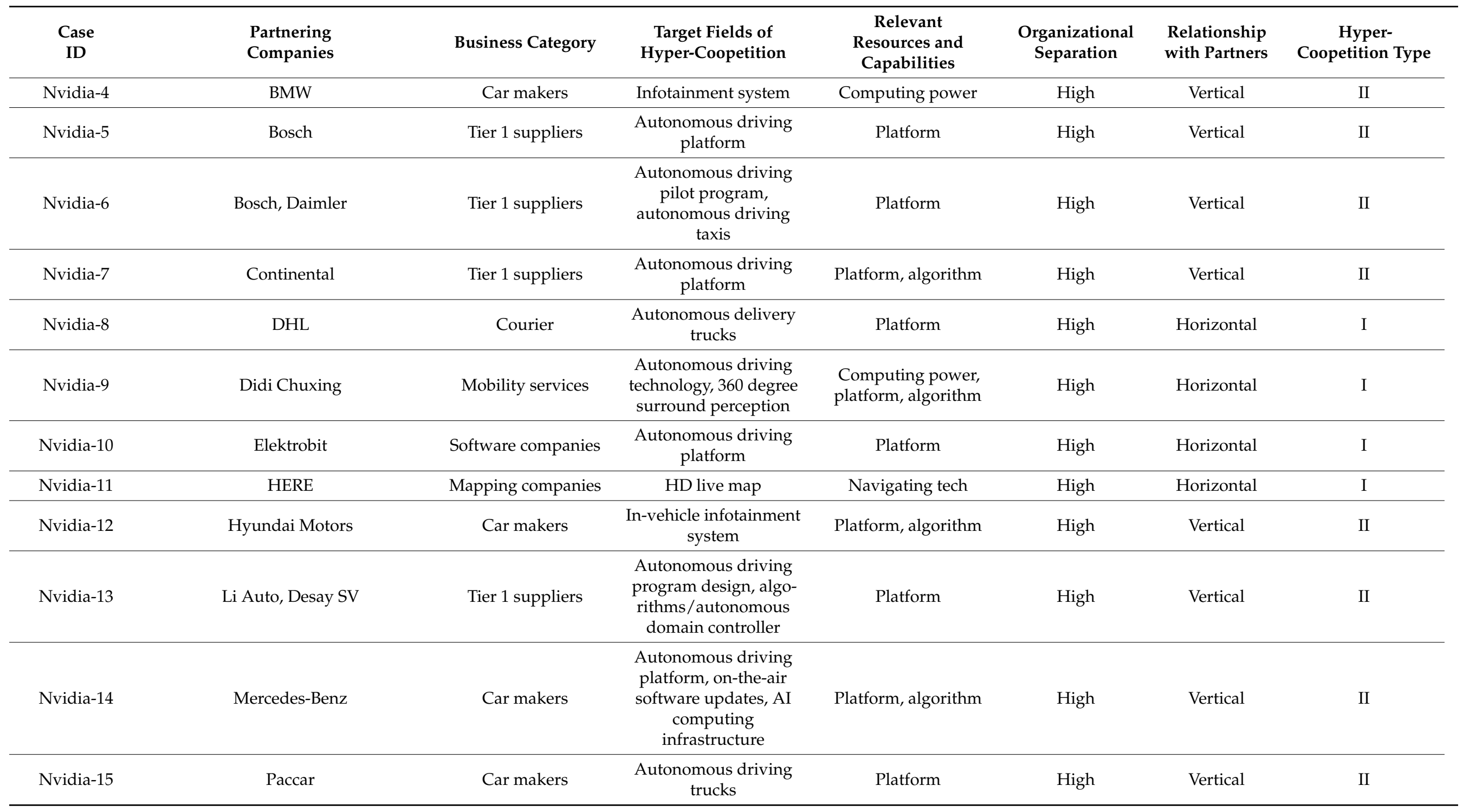


Table A1. Cont.

\begin{tabular}{|c|c|c|c|c|c|c|c|}
\hline $\begin{array}{l}\text { Case } \\
\text { ID }\end{array}$ & $\begin{array}{l}\text { Partnering } \\
\text { Companies }\end{array}$ & Business Category & $\begin{array}{c}\text { Target Fields of } \\
\text { Hyper-Coopetition }\end{array}$ & $\begin{array}{c}\text { Relevant } \\
\text { Resources and } \\
\text { Capabilities }\end{array}$ & $\begin{array}{l}\text { Organizational } \\
\text { Separation }\end{array}$ & $\begin{array}{l}\text { Relationship } \\
\text { with Partners }\end{array}$ & $\begin{array}{c}\text { Hyper- } \\
\text { Coopetition Type }\end{array}$ \\
\hline Nvidia-16 & SK Telecom & $\begin{array}{l}\text { Communication } \\
\text { services }\end{array}$ & $\begin{array}{l}\text { Autonomous driving } \\
\text { technology, 3D HD map }\end{array}$ & Platform, algorithm & High & Horizontal & I \\
\hline Nvidia-17 & Tesla & Car makers & In-car display & Computing power & High & Vertical & II \\
\hline Nvidia-18 & TomTom & Mapping companies & $\begin{array}{l}\text { Real-time in-vehicle } \\
\text { localization, } \\
\text { cloud-to-car mapping } \\
\text { system }\end{array}$ & Platform, algorithm & High & Horizontal & I \\
\hline Nvidia-19 & Toyota & Car makers & $\begin{array}{l}\text { Autonomous driving } \\
\text { platform }\end{array}$ & Platform, algorithm & High & Vertical & II \\
\hline Nvidia-20 & Unity Technologies & Software companies & $\begin{array}{l}\text { Autonomous driving } \\
\text { platform }\end{array}$ & Navigating tech & High & Horizontal & I \\
\hline Nvidia-21 & VinFast & Car makers & $\begin{array}{l}\text { Autonomous driving } \\
\text { electric vehicle }\end{array}$ & Platform & High & Vertical & II \\
\hline Nvidia-22 & Volvo & Car makers & $\begin{array}{l}\text { Autonomous driving } \\
\text { vehicle, Automotive } \\
\text { software, } 360 \text { degree } \\
\text { surround perception }\end{array}$ & Platform, algorithm & High & Vertical & II \\
\hline Nvidia-23 & Volkswagen & Car makers & $\begin{array}{l}\text { Cockpit, intelligent } \\
\text { copilot applications }\end{array}$ & Platform & High & Vertical & II \\
\hline Nvidia-24 & XPENG Motors & Car makers & $\begin{array}{l}\text { Autonomous driving } \\
\text { software platform }\end{array}$ & Platform & High & Vertical & II \\
\hline Nvidia-25 & Zenrin & Mapping companies & Digital map & Navigating tech & High & Horizontal & I \\
\hline Nvidia-26 & $\mathrm{ZF}$ & Tire 1 suppliers & $\begin{array}{l}\text { Autonomous driving } \\
\text { platform }\end{array}$ & Platform & High & Vertical & II \\
\hline Nvidia-27 & ZF, Hella & Tier 1 suppliers & $\begin{array}{l}\text { Autonomous driving } \\
\text { platform }\end{array}$ & Platform & High & Vertical & II \\
\hline Samsung-1 & Harman International & Tier 1 suppliers & $\begin{array}{l}\text { In-vehicle infotainment, } \\
\text { digital cockpit }\end{array}$ & $\begin{array}{l}\text { Computing power, } \\
\text { connectivity, } \\
\text { automotive electronics }\end{array}$ & Low & Horizontal & IV \\
\hline
\end{tabular}




\section{References}

1. Zacharia, Z.; Plasch, M.; Mohan, U.; Gerschberger, M. The Emerging Role of Coopetition within Inter-Firm Relationships. Int. J. Logist. Manag. 2019, 30, 414-437. [CrossRef]

2. Bouncken, R.B.; Gast, J.; Kraus, S.; Bogers, M. Coopetition: A Systematic Review, Synthesis, and Future Research Directions. Rev. Manag. Sci. 2015, 9, 577-601. [CrossRef]

3. Faccin, K.; Balestrin, A.; Volkmer Martins, B.; Bitencourt, C.C. Knowledge-Based Dynamic Capabilities: A Joint R\&D Project in the French Semiconductor Industry. J. Knowl. Manag. 2019, 23, 439-465. [CrossRef]

4. Yami, S.; Castaldo, S.; Dagnino, G.B.; Le Roy, F. Coopetition: Winning Strategies for the 21st Century; Edward Elgar Publishing: Cheltenham, UK, 2010.

5. Dowling, M.J.; Roering, W.D.; Carlin, B.A.; Wisnieski, J. Multifaceted Relationships under Coopetition: Description and Theory. J. Manag. Inq. 1996, 5, 155-167. [CrossRef]

6. Fernandes, C.I.; Ferreira, J.J.; Veiga, P.M.; Marques, C. The Effects of Coopetition on the Innovation Activities and Firm Performance: Some Empirical Evidence. Compet. Rev. 2019, 29, 622-645. [CrossRef]

7. Crick, J.M. The Facets, Antecedents and Consequences of Coopetition: An Entrepreneurial Marketing Perspective. Qual. Mark. Res. 2018, 21, 253-272. [CrossRef]

8. Osarenkhoe, A. A Study of Inter-Firm Dynamics between Competition and Cooperation-A Coopetition Strategy. J. Database Mark. Cust. Strategy Manag. 2010, 17, 201-221. [CrossRef]

9. Balkytè, A.; Tvaronavičienè, M. Perception of competitiveness in the context of sustainable development: Facets of "sustainable competitiveness". J. Bus. Econ. Manag. 2010, 11, 341-365. [CrossRef]

10. Walley, K. Coopetition: An Introduction to the Subject and an Agenda for Research. Int. Stud. Manag. Organ. 2007, 37, 11-31. [CrossRef]

11. Christ, K.L.; Burritt, R.L.; Varsei, M. Coopetition as a Potential Strategy for Corporate Sustainability. Bus. Strategy Environ. 2017, 26, 1029-1040. [CrossRef]

12. Kraus, S.; Klimas, P.; Gast, J.; Stephan, T. Sleeping with Competitors: Forms, Antecedents and Outcomes of Coopetition of Small and Medium-Sized Craft Beer Breweries. Int. J. Entrep. Behav. Res. 2019, 25, 50-66. [CrossRef]

13. Cygler, J.; Sroka, W.; Solesvik, M.; Dębkowska, K. Benefits and Drawbacks of Coopetition: The Roles of Scope and Durability in Coopetitive Relationships. Sustainability 2018, 10, 2688. [CrossRef]

14. Czakon, W.; Klimas, P.; Mariani, M. Behavioral Antecedents of Coopetition: A Synthesis and Measurement Scale. Long Range Plan. 2020, 53, 101875. [CrossRef]

15. Yoon, S.Y.; Jee, S.J.; Sohn, S.Y. Mapping and Identifying Technological Coopetition: A Multi-Level Approach. Scientometrics 2021, 126, 5797-5817. [CrossRef]

16. Anzenbacher, A.; Wagner, M. The Role of Exploration and Exploitation for Innovation Success: Effects of Business Models on Organizational Ambidexterity in the Semiconductor Industry. Int. Entrep. Manag. J. 2020, 16, 571-594. [CrossRef]

17. Pellens, M.; Della Malva, A. Corporate Science, Firm Value, and Vertical Specialization: Evidence from the Semiconductor Industry. Ind. Corp. Change 2018, 27, 489-505. [CrossRef]

18. Kim, J.H.; Chun, M.Y.S.; Nhung, D.T.H.; Lee, J. The Transition of Samsung Electronics through Its M \& A with Harman International. J. Open Innov. Technol. Mark. Complex. 2019, 5, 51. [CrossRef]

19. Deloitte Semiconductors - The Next Wave, Opportunities and Winning Strategies for Semiconductor Companies; Deloitte: New York, NY, USA, 2019

20. Bauer, H.; Burkacky, O.; Kenevan, P.; Mahindroo, A.; Patel, M. How the Semiconductor Industry Can Emerge Stronger after the COVID 19 Crisis; McKinsey Co: New York, NY, USA, 2020.

21. Duane Ireland, R.; Webb, J.W. Strategic Entrepreneurship: Creating Competitive Advantage through Streams of Innovation. Bus. Horiz. 2007, 50, 49-59. [CrossRef]

22. Ritala, P.; Sainio, L.M. Coopetition for Radical Innovation: Technology, Market and Business-Model Perspectives. Technol. Anal. Strateg. Manag. 2014, 26, 155-169. [CrossRef]

23. Krzanich, B. Waymo and Intel Collaborate on Self-Driving Car Technology; Intel Newsroom: Santa Clara, CA, USA, 2017.

24. Morris, M.H.; Koçak, A.; Ozer, A. Coopetition as a Small Business Strategy: Implications for Performance. J. Small Bus. Strategy 2007, 18, 35-56.

25. Crick, J.M.; Crick, D.; Chaudhry, S. The Dark-Side of Coopetition: It's Not What You Say, but the Way That You Do It. J. Strateg. Mark. 2020, 1-23. [CrossRef]

26. Ireland, R.D.; Hitt, M.A.; Sirmon, D.G. A Model of Strategic Entrepreneurship: The Construct and Its Dimensions. J. Manag. 2003, 29, 963-989. [CrossRef]

27. Hitt, M.A.; Ireland, D.R.; Camp, M.; Sexton, D.L. Guest editors' introduction to the special issue strategic entrepreneurship: Entrepreneurial strategies for wealth creationguest editors' introduction to the special issue strategic entrepreneurship: Entrepreneurial strategies for wealth creation. Strateg. Manag. J. 2001, 22, 479-492. [CrossRef]

28. Shakeel, J.; Mardani, A.; Chofreh, A.G.; Goni, F.A.; Klemeš, J.J. Anatomy of Sustainable Business Model Innovation. J. Clean. Prod. 2020, 261, 121201. [CrossRef]

29. Dorn, S.; Schweiger, B.; Albers, S. Levels, Phases and Themes of Coopetition: A Systematic Literature Review and Research Agenda. Eur. Manag. J. 2016, 34, 484-500. [CrossRef] 
30. Bouncken, R.B.; Fredrich, V.; Kraus, S. Configurations of Firm-Level Value Capture in Coopetition. Long Range Plan. 2020, 53, 101869. [CrossRef]

31. Lavie, D. Capturing Value from Alliance Portfolios. Organ. Dyn. 2009, 38, 26-36. [CrossRef]

32. Brandenburger, A.M.; Nalebuff, B.J. Co-Opetition; Currency Doubleday: New York, NY, USA, 2011; ISBN 0307790541.

33. Hora, W.; Gast, J.; Kailer, N.; Rey-Marti, A.; Mas-Tur, A. David and Goliath: Causes and Effects of Coopetition between Start-Ups and Corporates. Rev. Manag. Sci. 2018, 12, 411-439. [CrossRef]

34. Blanka, C.; Traunmüller, V. Blind Date? Intermediaries as Matchmakers on the Way to Start-up-Industry Coopetition. Ind. Mark. Manag. 2020, 90, 1-13. [CrossRef]

35. Runge, S.; Schwens, C.; Schulz, M. The Invention Performance Implications of Coopetition: How Technological, Geographical, and Product Market Overlaps Shape Learning and Competitive Tension in R\&D Alliances. Strateg. Manag. J. 2021. epub ahead of print. [CrossRef]

36. Dussauge, P.; Garrette, B.; Mitchell, W. Learning from Competing Partners: Outcomes and Durations of Scale and Link Alliances in Europe, North America and Asia. Strateg. Manag. J. 2000, 21, 99-126. [CrossRef]

37. Bengtsson, M.; Kock, S. "Coopetition" in Business Networks-To Cooperate and Compete Simultaneously. Ind. Mark. Manag. 2000, 29, 411-426. [CrossRef]

38. Bengtsson, M.; Kock, S.; Lundgren-Henriksson, E.L.; Näsholm, M.H. Coopetition Research in Theory and Practice: Growing New Theoretical, Empirical, and Methodological Domains. Ind. Mark. Manag. 2016, 57, 4-11. [CrossRef]

39. Czakon, W. Network Coopetition. In Routledge Companion to Coopetition Strategies; Routledge: Oxfordshire, UK, 2018.

40. Hani, M.; Dagnino, G.B. Global Network Coopetition, Firm Innovation and Value Creation. J. Bus. Ind. Mark. 2021, 36, 1962-1974. [CrossRef]

41. Hečková, J.; Štefko, R.; Frankovský, M.; Birknerová, Z.; Chapčáková, A.; Zbihlejová, L. Cross-Border Mergers and Acquisitions as a Challenge for Sustainable Business. Sustainability 2019, 11, 3130. [CrossRef]

42. Ahmad, A. Automotive Semiconductor Industry-Trends, Safety and Security Challenges. In Proceedings of the ICRITO 2020IEEE 8th International Conference on Reliability, Infocom Technologies and Optimization (Trends and Future Directions), Noida, India, 4-5 June 2020.

43. Kato, S.; Tokunaga, S.; Maruyama, Y.; Maeda, S.; Hirabayashi, M.; Kitsukawa, Y.; Monrroy, A.; Ando, T.; Fujii, Y.; Azumi, T. Autoware on Board: Enabling Autonomous Vehicles with Embedded Systems. In Proceedings of the 9th ACM/IEEE International Conference on Cyber-Physical Systems, ICCPS, Porto, Portugal, 11-13 April 2018.

44. Jantunen, A.; Puumalainen, K.; Saarenketo, S.; Kyläheiko, K. Entrepreneurial Orientation, Dynamic Capabilities and International Performance. J. Int. Entrep. 2005, 3, 223-243. [CrossRef]

45. Eisenhardt, K.M. Building Theories from Case Study Research. Acad. Manag. Rev. 1989, 14, 532-550. [CrossRef]

46. Eisenhardt, K.; GRAEBNER, M. Theory Building from Cases: Opportunities and Challenges. Acad. Manag. J. 2007, 50, 25-32. [CrossRef]

47. Dooley, L.M. Case Study Research and Theory Building. Adv. Dev. Hum. Resour. 2002, 4, 335-354. [CrossRef]

48. Yin, R.K. Case Study Research: Design and Methods, 4th ed.; Sage Publications: Thousand Oaks, CA, USA, 2009 ; Volume 14.

49. Given, L. The SAGE Encyclopedia of Qualitative Research Methods; Sage Publications: Thousand Oaks, CA, USA, 2012.

50. Paek, B.; Lee, H.; Entrep Manag, I.J. Strategic Entrepreneurship and Competitive Advantage of Established Firms: Evidence from the Digital TV Industry. Int. Entrep. Manag. J. 2017, 14, 883-925. [CrossRef]

51. Ireland, R.D.; Covin, J.G.; Kuratko, D.F. Conceptualizing Corporate Entrepreneurship Strategy. Entrep. Theory Pract. 2009, 33, 19-46. [CrossRef]

52. Lewis-Beck, M.; Bryman, A.; Futing Liao, T. The SAGE Encyclopedia of Social Science Research Methods; Sage Publications: Thousand Oaks, CA, USA, 2012.

53. Saldaña, J. The Coding Manual for Qualitative Researchers; Sage Publications: Thousand Oaks, CA, USA, 2009.

54. Moon, S.; Lee, H. The Role of Standards-Related Capacity Building on the Sustainable Development of Developing Countries: Focusing on the Korea's Standards-Related AfT Case in Bolivia. Sustainability 2020, 12, 5199. [CrossRef]

55. Geertz, C. Thick Description: Toward an Interpretive Theory of Culture. In Interpretation of Cultures; Basic Books: New York, NY, USA, 1973.

56. Akpinar, M.; Vincze, Z. The Dynamics of Coopetition: A Stakeholder View of the German Automotive Industry. Ind. Mark. Manag. 2016, 57, 53-63. [CrossRef] 